\title{
Gastro-intestinal Helminthiasis among School Children in Gokana and Khana Local Government Areas of Rivers State, Nigeria
}

\section{Abah $\mathrm{AE}^{*}$ and Awi-Waadu GDB}

Department of Animal and Environmental Biology, Faculty of Science, University of Port Harcourt. Rivers State, Nigeria

\begin{abstract}
Gastro-intestinal helminthias is a macroparasitic disease caused by parasitic worms known as helminths which infect the Gastro-Intestinal Tract (GIT) of humans and other animals. The disease can potentially cause health problems as a result of the damage arising from the pathogenicity of the infections especially in children. This study therefore assessed the gastro-intestinal helminthiasis among primary school children in Gokana and Khana Local Government Areas (LGAs) of Rivers State. A total of 633 stool samples were collected and examined in duplicate using the standard methods of saline/iodine and formol-ether concentrations. The overall prevalence of gastro-intestinal helminthiasis in the two LGAs was $21.0 \%$ of which $24.3 \%$ and $17.4 \%$ were recorded for Gokana and Khana respectively. There was significant difference in infection rate between the two LGAs, being higher in Gokana than in Khana at $P=0.02394$. Sex related prevalence showed higher rate in males $(31.1 \%)$ than females $(18.5 \%)$ in Gokana and $22.3 \%$ in males than in females $13.0 \%$ in Khana Parasites recovered included Ascaris lumbricoides which had the highest prevalence in both Gokana (32.1\%) and Khana (45.5\%) followed by hookworm 24.4\%, 23.6\%, Trichuris trichiura $16.7 \%$, $18.2 \%$ and Strongyloides stercoralis 5.1\%, 3.6\% for Gokana and Khana respectively. Multiple infections were encountered in both Local Government Areas with Ascaris hookworm combinations being the highest and most common in both areas. This study concludes that the prevalence of gastro- intestinal helminthiasis among school children in Gokana and Khana Local Government Areas is relatively high, therefore, there is need to step up effort towards the control of these parasites through improve sanitation and health education.
\end{abstract}

Keywords: Gastro-intestinal; Helminthiasis; Infection; Prevalence; Rivers state

\section{Introduction}

Intestinal parasites are parasites that populate the gastro-intestinal tract in humans and other animals and are among the most common infections worldwide [1,2]. Risk factors associated with intestinal parasitic infections include ignorance, poverty, malnutrition and squalor and hence the infections affect the poorest and most deprived communities. The infection negatively affect nutritional status and according to WHO [3], causing complications that require surgical intervention. This poses an untold harvest of damage and hence a major public health problem. It is acquired through contaminated and uncooked or undercooked food, water and from hand to mouth where there is poor hygiene.

According to WHO current estimate, approximately, more than 1.5 billion people (one-sixth of the world's population), which is about $24 \%$ of the world's population, are infected with intestinal parasitic infection worldwide [3]. Infections are widely distributed in tropical and subtropical areas, with the greatest numbers occurring in subSaharan Africa, the Americas, China and East Asia. Latest estimates indicate that more than 880 million children are in need of treatment for these parasites [3].

Nigeria has the highest burden of endemicity of intestinal helminth infections in Africa. Prevailing environmental conditions such as temperature, humidity, rainfall and poor sanitation promotes the transmission of the parasites. Intestinal parasitic infections have been reported to have high prevalence among children in Nigeria who are mostly infected because of their high level of vulnerability to nutritional deficiency [4-10]. Although, the prevalence varies from place to place in relation to pattern of transmission of the disease [11].

In Rivers State, Intestinal Parasitic infection has been shown to have high prevalence especially in children [10,12]. Acquiring epidemiological information on the prevalence of intestinal parasitic infections in different localities is a necessary requirement that would enhance the development of appropriate control strategies. Although some of these reports exist, none, to our knowledge compared prevalence at the local government levels which is the closest government to the people. This study was aimed at assessing and comparing the prevalence of gastro-intestinal parasitic infections in Gokana and Khana LGAs in Rivers State.

\section{Materials and Methods}

\section{Study area}

The study was conducted in two Local Government Areas (LGAs) in Rivers State, Nigeria The LGAs selected were Gokana and Khana which are situated at latitudes $4^{\circ} 33^{\prime}$ and $4^{\circ} 50^{\prime} \mathrm{N}$ and longitudes $7^{\circ} 20^{\prime}$ and $7^{\circ} 35^{\prime} \mathrm{E}$ in the eastern part of Port Harcourt in Rivers State generally referred to as Ogoniland and on the coast of gulf of Guinea (Figure 1). The area has an annual total rainfall between $160 \mathrm{~mm}$ and $298 \mathrm{~mm}$; relative humidity of over $90 \%$ and mean temperature of $27^{\circ} \mathrm{C}$. The people are predominantly farmers, fishermen, artisans and traders while a few are civil servants. The coordinates of the sampling location is presented in Table 1 [13].

\section{Sampling procedures}

Ethical consideration: The guidelines laid down in the Declaration of Helsinki 2013 for procedures involving human subjects were strictly adhered to; hence ethical clearance for the study was sought and granted by the research management and development committee of the University

*Corresponding author: Abah AE, Department of Animal and Environmenta Biology, Faculty of Science, University of Port Harcourt. Rivers State, Nigeria, Tel: +2348033402311; Email: austin.abah@uniport.edu.ng

Received: August 20, 2018; Accepted: October 09, 2018; Published: October 16, 2018

Citation: Abah AE, Awi-Waadu GDB (2018) Gastro-intestinal Helminthiasis among School Children in Gokana and Khana Local Government Areas of Rivers State, Nigeria. Prim Health Care 8: 311. doi: 10.4172/2167-1079.1000311

Copyright: ( $2018 \mathrm{Abah} \mathrm{AE}$, et al. This is an open-access article distributed unde the terms of the Creative Commons Attribution License, which permits unrestricted use, distribution, and reproduction in any medium, provided the original author and source are credited. 


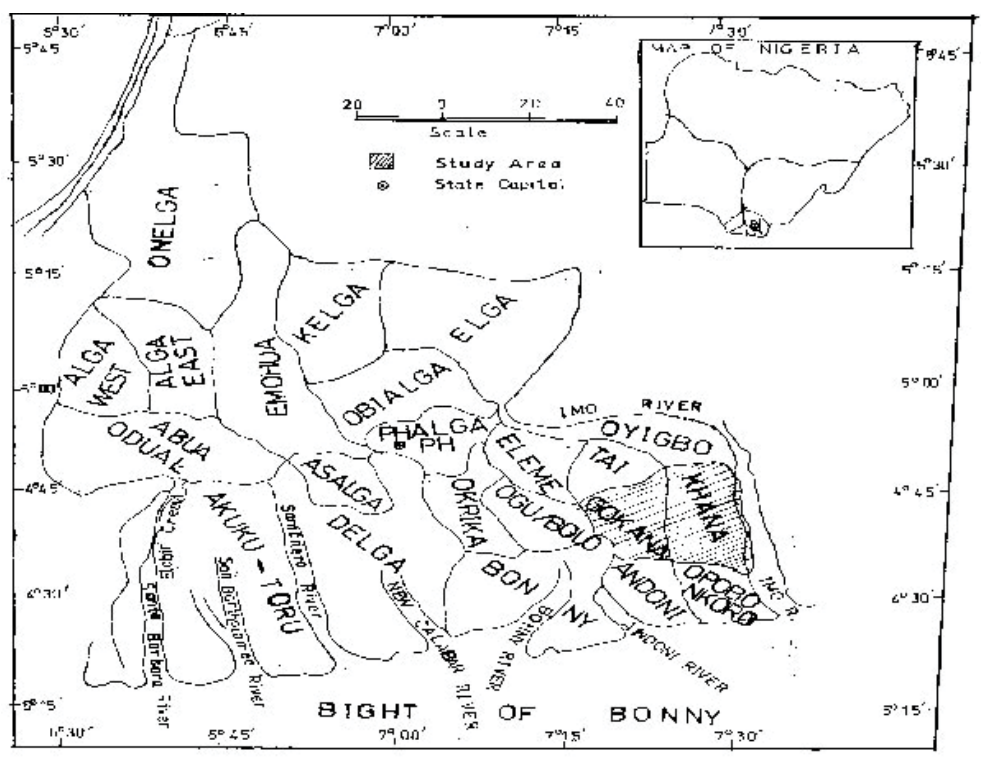

Figure 1: Map of Rivers state showing the study area [13]

\begin{tabular}{|c|c|c|c|c|c|}
\hline LGA & Primary School & Co-ordinates & & Temp $\left({ }^{\circ} \mathrm{C}\right)$ & Rel.Humidity (\%) \\
\hline \multirow[t]{3}{*}{ Gokana } & Bodo city primary school (1) & $04^{\circ} 37^{\prime} 30.0^{\prime \prime} \mathrm{N}$ & $007^{\circ} 27^{\prime} 48.9^{\prime \prime} \mathrm{E}$ & 31.0 & 73.8 \\
\hline & Community pri school 1 Yeghe & $00^{\circ} 41^{\prime} 03.6^{\prime \prime} \mathrm{N}$ & $007^{\circ} 20^{\prime} 49.8^{\prime \prime} \mathrm{E}$ & 32.5 & 72.3 \\
\hline & Primary School 1 Mogho & $04^{\circ} 39^{\prime} 07.2^{\prime \prime} \mathrm{N}$ & $007^{\circ} 17^{\prime} 24.0^{\prime \prime} \mathrm{E}$ & 33.0 & 66.6 \\
\hline \multirow[t]{3}{*}{ Khana } & Community Primary school 1 & $04^{\circ} 03^{\prime} 8.9^{\prime \prime} \mathrm{N}$ & $007^{\circ} 16^{\prime} 26.1 " \mathrm{E}$ & 30.9 & 67 \\
\hline & Primary School IV Bori & $04^{\circ} 40^{\prime} 31.9^{\prime \prime} \mathrm{N}$ & $007^{\circ} 2^{\prime} 50.9^{\prime \prime} \mathrm{E}$ & 33.0 & 82.3 \\
\hline & Community primary Sch1 and UBE II Wiiyaakara & $04^{\circ} 39^{\prime} 43.4^{\prime \prime} \mathrm{N}$ & $007^{\circ} 25^{\prime} 36.1^{\prime \prime} \mathrm{E}$ & 31.6 & 75.5 \\
\hline
\end{tabular}

Table 1: Schools sampled in Gokana and Khana local government areas.

of Port Harcourt and the State Ministry of Health. Informed consents were obtained from heads of schools, teachers and parents in the LGAs.

Sample size: The sample size calculation was based on the formula by Daniel [14] and modified by Naing et al. [15]. It was calculated using the single proportion population formula based on a prevalence of $83 \%$ with a margin of error of 0.05 and a confidence level of $95 \%$. The design effect was calculated by taking the interclass correlation for the statistic (i.e. 1\%) in parasitic infection in the 2 LGAs. From each Local Government Area (LGA), 310 samples were arrived at but a total of 633 samples were analysed from the two LGAs.

Sample collection: Stool samples were collected in a clean universal bottle from 633 pupils randomly selected from the primary schools in the two local government areas. The samples were transported to the Animal and Environmental Biology of the University of Port Harcourt for Examination.

Stool examination: Stool samples collected were examined in duplicate using standard saline/iodine and formol-ether concentration method as described by WHO [16] and Cheesbrough [17].

Direct wet preparation method: A drop of physiological saline was placed on a clean grease-free slide. With the aid of an applicator stick, a little quantity of properly mixed stool sample was emulsified. The same procedure was repeated using iodine and the preparation covered with a coverslip and examined with $100 x$ and finally with $400 x$ magnifications of the light microscope.
Concentration method: Stool samples were concentrated using formol ether concentration technique. One millilitre of a well-mixed stool sample was put in a tube containing $4 \mathrm{~mL}$ of $10 \%$ formalin. 3 $\mathrm{mL}$ of the $10 \%$ formalin was again added and mixed by shaking. The suspension was sieved using a coffee strainer into a centrifuge tube. $3 \mathrm{~mL}$ of diethyl ether was added and stoppered. It was then shaken vigorously for $1 \mathrm{~min}$. The stopper was removed and the suspension centrifuged for $1 \mathrm{~min}$ at $400 \mathrm{rpm}$. The entire column of the fluid below the faecal debris and ether was carefully removed using a Pasteur pipette and transferred into another centrifuge tube. $10 \%$ formalin was added to the transferred suspension to make up to $10 \mathrm{~mL}$. It was then centrifuged at $1000 \mathrm{rpm}$ for $10 \mathrm{~min}$. The supernatant was decanted and the bottom of the tube tapped to re-suspend the deposit. The deposit was examined under the microscope at 100x and 400x magnifications respectively for the presence of ova or cysts of parasites.

\section{Data analysis}

Proportions obtained in the study were analysed using percentage and descriptive statistics.

\section{Results}

The overall prevalence of intestinal parasitic infection in the two LGAs was $21.0 \%$ of which Gokana had $24.3 \%$ and Khana had $17.4 \%$ (Table 2) Infection rate was significantly higher in Gokana than Khana $(\mathrm{P}=0.02394)$. Sex related infection showed that infection rate was higher among males $(31.1 \%)$ than females (18.5\%) in Gokana as well as 


\begin{tabular}{|c|c|c|c|}
\hline LGA & No Examined & No Infected & Infected (\%) \\
\hline Gokana & 321 & 78 & 24.3 \\
\hline Khana & 312 & 55 & 17.6 \\
\hline Total & $\mathbf{6 3 3}$ & $\mathbf{1 3 3}$ & $\mathbf{2 1 . 0}$ \\
\hline
\end{tabular}

Table 2: Overall prevalence of Intestinal Parasitic infection in Gokana and Khana LGAs.

\begin{tabular}{|l|c|c|c|c|c|c|}
\hline & \multicolumn{2}{|c|}{ Gokana } & & Khana & & \\
\hline & Male & Female & Total & Male & Female & Total \\
\hline No Examined & 148 & 173 & 321 & 148 & 169 & 312 \\
\hline No Infected & 46 & 32 & 78 & 33 & 22 & 55 \\
\hline Infected (\%) & $\mathbf{3 1 . 1}$ & $\mathbf{1 8 . 5}$ & $\mathbf{2 4 . 3}$ & $\mathbf{2 2 . 3}$ & $\mathbf{1 3}$ & $\mathbf{1 7 . 4}$ \\
\hline
\end{tabular}

Table 3: Sex related prevalence of intestinal parasitic infection in Gokana and Khana LGAs.

\begin{tabular}{|l|c|c|c|c|}
\hline & Ascaris & Hookworm & T.T & Strongy \\
\hline Gokana/78 & $25(32.1 \%)$ & $19(24.4 \%)$ & $13(16.7 \%)$ & $4(5.1 \%)$ \\
\hline Khana/55 & $25(45.5 \%)$ & $13(23.6 \%)$ & $10(18.2 \%)$ & $2(3.6 \%)$ \\
\hline
\end{tabular}

Key: TT=Trichuris trichiura, Strongy=Strongyloides stercoralis.

Table 4: Prevalence in relation to type of intestinal parasitic infection in Gokana and Khana LGAs.

\begin{tabular}{|l|c|c|c|c|}
\hline & As+TT & AS+HW & TT+HW & AS+TT+HW \\
\hline Gokana & $6(7.7 \%)$ & $2(2.6 \%)$ & $2(2.6 \%)$ & $3(3.8 \%)$ \\
\hline Khana & $4(7.3 \%)$ & $2(3.6 \%)$ & $2(3.6 \%)$ & 0 \\
\hline
\end{tabular}

Key: As=Ascaris lumbricoides, $\mathrm{TT}=$ Trichuris trichiura, $\mathrm{HW}=$ hookworm.

Table 5: Prevalence of Multiple Infections of intestinal parasites in Gokana and Khana LGAs.

in Khana where the infection rate was $22.3 \%$ and $13.0 \%$ for males and females respectively (Table 3 ). Single species prevalence of intestinal parasitic infection showed Ascaris lumbricoides as the highest in both Gokana (32.1\%) and Khana (45.5\%) followed by hookworm $24.4 \%$, $23.6 \%$, Trichuris trichiura 16.7\%, 18.2\% and Strongyloides stercoralis 5.1\%, 3.6\% for both Gokana and Khana respectively (Table 4). Multiple species infections were recorded in both Local Government Areas with the combination of A. lumbricoides and Trichuris trichiura being the highest in both areas (Table 5).

\section{Discussion}

The overall prevalence of intestinal helminthiasis in the study area was $21.3 \%$ and it is relatively high. This is of public health importance as the current figure is higher than $19.3 \%$ reported by Hassan et al. [18] in Ibadan thus corroborating the fact that intestinal parasitic infection among school age children remains endemic in Nigeria. This calls for regular surveillance to guide policy makers in proper application of scare resources. However, the current overall prevalence of $21.3 \%$ is lower than $27.66 \%$ earlier reported by Abah and Arene [10]; $30.7 \%$ by Odu and $84.6 \%$ by Awi-Waadu [12] in Rivers State. The observed decline may be attributed to the fact that in Nigeria, there have been sporadic de-worming programmes undertaken by government at all levels. Rivers State Government has also been involved in the school deworming exercise to reduce infant morbidity and mortality. In addition, there has been vigorous campaign to improve environmental sanitation and personal hygiene and constructions of modern classrooms in many communities of the state have been embarked upon. The decline observed in the present study is not limited to Rivers State or Nigeria but also globally where there has been a reported decline of intestinal parasitic infection from 3.5 billion people in 1998 [2] to 1.5 billion in 2018 [3]. It was observed that higher prevalence of infection occurred in Gokana (24.3\%) than Khana (17.4\%). The difference in infection prevalence between the two LGAs was significant at $\mathrm{P}=0.02394$. This agrees with the established fact that the prevalence of infection varies from place to place in relation to pattern of the transmission of the disease [11]. Sex related infection showed that more males were infected than females in both local Government areas. This finding agrees with earlier works by Abah and Arene [19] and Odu where it was reported that more males engage in outdoor activities such as farming and playing in the sands than their female counterparts [20].

The frequency of parasites identified showed that, Ascaris lumbricoides had the highest frequency $32.1 \%$ in Gokana and $45.5 \%$ in Khana LGAs. This observation agrees with previous studies by Hassan et al. [18], Abah and Arene [19], Odu and Awi-Waadu [12] and may be attributed to the capacity of the embryonated eggs to withstand harsh environmental conditions for long period. Prevalence of multiple infections was also recorded in this study and the combination of $A$. lumbricoides and Trichuris trichiura was predominant in both LGAs. This observation indeed reaffirms WHO report [3] that A. lumbricoides, T. trichiura, hookworms and Strongyloides stercoralis are the most frequently encountered helminthes in the tropics.

In conclusion, the prevalence of gastro-intestinal helminthiasis among school children in Gokana and Khana Local Government Areas is relatively high and significantly different between the two LGAs. The need to step up effort towards the control of these parasites through improvement in sanitation and health education is advocated.

\section{Conflict of Interest}

The authors declare that there is no conflict of interest.

\section{References}

1. Kang G, Mathew MS, Rajan DP, Daniel JD, Mathan MM (1998), Prevalence of intestinal parasites in rural southern India. Trop Med Int Health 3: 70-75.

2. World Health Organization (1998) Intestinal parasitic control: Burden and trends.

3. World Health Organization (2018) Intestinal worms.

4. Ejezie GC, Igwe MA (1993) Human ecology and parasitic infections in Nigeria It's relationship between parasitic and anaemia. J Med Laboratory 3: 22-26.

5. Awogun IA, Okwerekwu FE, Ogawoye OA, Bello AB (1995) Helminthic infection and anaemia among pregnant women attending antenatal clinic in Ilorin Nigeria. Nigeria Bioscience-Res Comm 7: 41-45.

6. Adeyeba OA, Akinlabi MA (2000) Intestinal parasitic infection among school children in rural community, South West Nigeria. Nigerian J Parasitol 28: 11-18.

7. Ledor K, Weller P (2002) Giadiasis. In: Rise BD (Eds.) Infections Disease Well Slay Mass.

8. Barnabas BB (2005) Prevalence of intestinal helminthiasis in school children from selected schools in Bida Nigeria. Nigeria J Applied Arts Sci 1: 22-26.

9. Sam-wobo SO, Mafiana CF, Amusan SA (2005) Health knowledge and hygiene behaviors in relation to Ascariasis among school children, Ogun State, Nigeria tanzan. Health Res Bull 7: 62-66.

10. Abah AE, Arene FOI (2015) Status of intestinal parasitic infections among primary school children in Rivers State, Nigeria. J Parasitol Res 15: 1-7.

11. Luka SA, Ajogi I, Umoh JU (2000) Helminthic among primary school children in Lere Local Govt. Area, Kaduna State Nigeria. The Nigerian. J Parasitol 21 109-116.

12. Awi-waadu GDB (2005) The prevalence of gastro-intestinal tract parasites in the inhabitants of Bori military cantonment in Port-Harcourt local govt. area of Rivers state, Nigeria. African J Applied Zoology and Environ Biol 7: 56-60.

13. Udom GJ, Ushie FA, Esu EOA (2002) Geochemical survey of groundwater in Khana and Gokana local government areas of Rivers state, Nigeria. J Applied Sciences Environ Manage 6: 53-59. 
Citation: Abah AE, Awi-Waadu GDB (2018) Gastro-intestinal Helminthiasis among School Children in Gokana and Khana Local Government Areas of Rivers State, Nigeria. Prim Health Care 8: 311. doi: 10.4172/2167-1079.1000311

14. Daniel WW (1999) Biostatics: A foundation for analysis in the health sciences New York: John Willey and Sons.

15. Naing L, Winn T, Rusli BN (2006) Sample size calculator for prevalence studies.

16. WHO (1991) Basic laboratory methods in medical parasitology.

17. Cheesbrough M (1999) District laboratory manual for tropical countries. Bulterworth-heinemann Ltd: Oxford, pp: 1-125.
18. Hassan AA, Arosoye AS, Oyebamiji DA (2018) Survey of human intestina parasites in communities within Ibadan, Southwestern, Nigeria. Acta Scientific Microbiol 1: 61-67.

19. Abah AE, Arene FOI (2016) Intestinal parasitic infections in three geographical zones of Rivers state, Nigeria. Nigerian J Parasitol: 37: 83-86.

20. Akinboye DO, Abdullah AR, Awodele O, Akintunde TI, Efffedua HI, et al. (2015) Prevalence of intestinal and urinary parasites among food handlers in llishanRemo Ogun state Nigeria. Nigerian J Parasitol 32: 113-118. 